\title{
Prevalence and determinants of smoking in three regions of Saudi Arabia
}

Jamal S Jarallah, Khalid A Al-Rubeaan, Abdul Rahman A Al-Nuaim, Atallah A Al-Ruhaily, Khalid A Kalantan

\begin{abstract}
Objectives-To study the prevalence and determinants of cigarette smoking among Saudi nationals in three regions of Saudi Arabia.

Participants-A sample of 8310 individuals aged 15 years and above from both sexes, randomly selected from the three regions, using a stratified cluster sampling technique.

Design-A cross-sectional, household, community-based survey. Using a predesigned and tested questionnaire, the participants were interviewed by primary care physicians. The interview covered personal, social, and educational characteristics of the respondents, and also included questions about their smoking status, duration of smoking, and daily cigarette consumption.
\end{abstract}

Main outcome measures-Association between current smoking and sociodemographic variables, in univariate and multivariate analysis. Degree of interaction between the different determinants of cigarette smoking.

Results-The overall prevalence of current smoking was $21.1 \%$ for males and $0.9 \%$ for females. Most smokers (78\%) were young to middle-aged (21-50 years old). Smoking prevalence was higher among married people, among uneducated people, and among those in certain occupations: manual workers, businessmen, army officers, and office workers. Conclusions-Cigarette smoking is an important public health problem in Saudi Arabia. A more intense and comprehensive tobacco control effort is needed.

(Tobacco Control 1999;8:53-56)

Department of Family and Community Medicine, King Saud University, Riyadh, Saudi Arabia J S Jarallah

K A Kalantan

Endocrinology Division, Department of Medicine

K A Al-Rubeaan A R A Al-Nuaim A A Al-Ruhaily

Correspondence to: Dr JS Jarallah, Department of Family and Community Medicine, College of Medicine, King Sau University, PO Box 2925

Riyadh 11461, Saudi Arabia; jamal@ksu.edu.sa
Saudi Arabia does not grow tobacco or man facture cigarettes, smoking has existed in this country for more than 50 years. Tobacco imports in the form of manufactured cigarettes have increased dramatically over the years, and an average of 600 million Saudi Riyals (about $\$ 150$ million) are spent annually on tobacco. ${ }^{3}$

No nationwide studies on the prevalence of tobacco smoking have been performed in Saudi Arabia. Small-scale studies have shown a prevalence of between $8 \%$ and $57 \%^{4-13}$; few of these, however, were community-based. ${ }^{12}$ We conducted a household survey to study the prevalence and determinants of cigarette smoking in three regions in Saudi Arabia, using the data from the national survey of chronic metabolic disorders.

\section{Methods}

The data for this study were obtained during a national cross-sectional survey of chronic metabolic disorders in Saudi Arabia, which was conducted between 1990 and 1993.

Saudi nationals, aged 15 years and older, were the target study population. After dividing the country into five provinces (west, east, central, north, and south), each province was further subdivided into a number of regions.

The sample size was determined based on the prevalence of diabetes mellitus in Saudi Arabia. As previous small-scale studies suggested that the prevalence of diabetes mellitus is in the range of $5-15 \%$, it was necessary to select a simple random sample of between 1825 and 4892 individuals. This would allow the calculation of an estimate which would be within one percentage point of the actual prevalence at a $95 \%$ level of probability.

A larger sample was selected for the study to ensure that the population under study was fully represented and that the sample was distributed among the regions proportionate to the size of the populations in each region. The sample was selected in a multistage, stratified cluster sampling procedure. The total sample size was divided among the five administrative provinces with a probability proportionate to the size of the population of each province. The sample was divided over the number of regions in each province with a probability proportionate to the size of each region. The sample was further subdivided over the number of localities with a probability proportionate to size, taking into consideration the urban-to-rural ratios in each region within each locality. Catchment areas of randomly selected health centres were used for recruiting the study population. A household survey was then conducted through random 
Table 1 Weighted prevalence of current smokers and non-smokers in the study population, according to various sociodemographic characteristics $(n=8310)$

\begin{tabular}{|c|c|c|c|c|c|}
\hline & $\begin{array}{l}\text { Smokers } \\
n(\%)\end{array}$ & $\begin{array}{l}\text { Non-smokers } \\
n(\%)\end{array}$ & Total & OR & $95 \% C I$ \\
\hline \multicolumn{6}{|l|}{ Occupation } \\
\hline Housewife & $60(0.8)$ & 7257 (99.2) & 7317 & 1.00 & \\
\hline Student & $225(5.5)$ & $3887(94.5)$ & 4112 & 7.00 & $5.21-9.43$ \\
\hline Farmer & $97(14.4)$ & $576(85.6)$ & 673 & 20.37 & $14.42-28.8$ \\
\hline Clerk & $726(22.8)$ & $2455(77.2)$ & 3181 & 35.77 & $27.18-47.17$ \\
\hline Army & $327(23.8)$ & $1045(76.2)$ & 1372 & 37.85 & $28.80-50.72$ \\
\hline Business & $355(28.7)$ & $881(71.3)$ & 1236 & 48.74 & $36.43-65.32$ \\
\hline Manual labourer & $93(27.4)$ & $247(72.0)$ & 340 & 45.54 & $31.69-65.50$ \\
\hline Others & $563(20.9)$ & $2126(79.1)$ & 2689 & 32.03 & $24.25-42.39$ \\
\hline \multicolumn{6}{|l|}{ Sex } \\
\hline Female & $88(0.9)$ & $9918(99.1)$ & 10006 & 1.00 & \\
\hline Male & $2403(21.1)$ & $8990(78.9)$ & 11393 & 30.13 & $24.19-37.57$ \\
\hline \multicolumn{6}{|l|}{ Education } \\
\hline Illiterate & $632(7.5)$ & $7818(92.5)$ & 8450 & 1.00 & \\
\hline Elementary & $675(16.4)$ & $3437(83.6)$ & 4112 & 2.43 & $2.16-2.73$ \\
\hline Intermediate & $525(15.9)$ & $2769(84.1)$ & 3294 & 2.35 & $2.07-2.66$ \\
\hline Secondary & $393(11.4)$ & $3062(88.6)$ & 3455 & 1.59 & $1.39-1.83$ \\
\hline University & $143(12.6)$ & $989(87.4)$ & 1132 & 1.79 & $1.47-2.18$ \\
\hline Technical & $36(13.5)$ & $230(86.5)$ & 266 & 1.94 & $1.33-2.81$ \\
\hline Others & $47(10.7)$ & $393(89.3)$ & 440 & 1.48 & $1.07-2.04$ \\
\hline \multicolumn{6}{|l|}{ Age (years) } \\
\hline $15-20$ & $325(6.7)$ & $4558(93.3)$ & 4883 & 1.00 & \\
\hline $21-30$ & $962(13.7)$ & $6035(86.3)$ & 6997 & 2.24 & $1.96-2.56$ \\
\hline $31-40$ & $699(15.8)$ & $3716(84.2)$ & 4415 & 2.64 & $2.29-3.04$ \\
\hline $41-50$ & $271(12.2)$ & $1951(87.8)$ & 2222 & 1.95 & $1.64-2.32$ \\
\hline $51-60$ & $135(8.2)$ & $1517(91.8)$ & 1652 & 1.25 & $1.01-1.55$ \\
\hline$\geqslant 61$ & $99(8.0)$ & $1131(92.0)$ & 1230 & 1.23 & $0.96-1.56$ \\
\hline \multicolumn{6}{|l|}{ Locality } \\
\hline Urban & $1310(11.6)$ & $9946(88.4)$ & 11256 & 1.00 & \\
\hline Rural & $1181(11.6)$ & $8962(88.4)$ & 10143 & 1.00 & $0.92-1.09$ \\
\hline
\end{tabular}

$\mathrm{OR}=$ odds ratios; $\mathrm{CI}=$ confidence intervals.

selection of every third house within the assigned catchment area.

All Saudi subjects aged 15 years or more were interviewed by primary care physicians. To the extent possible, the interview was personal and private; however, sometimes it was difficult to achieve total privacy. The overall survey response rate was $87.8 \%$. The interview covered personal, social, and educational characteristics of respondents, and also asked questions about their smoking status, duration of smoking, and daily cigarette consumption. Current smoking was defined as smoking one or more cigarettes daily for six months or more before the survey.

The data were entered into a personal computer using the SPSS (version 6) statistical package. ${ }^{14}$ The $\chi^{2}$ test was used to compare smokers and non-smokers for the categorical variables and the $t$ test was used to compare the means of quantitative data. The $\chi^{2}$ test for trend was used to assess the change in the probability of smoking across the categories of the determinant variables. The data were weighted to calculate the frequencies in all of the five regions and to assess if there was a significant difference after weighting, according to the method described by Robins et al. ${ }^{15}$

For the multivariate analysis, a stepwise logistic regression was used. Odds ratios (ORs) with $95 \%$ confidence intervals (CIs) for each variable were calculated as an estimate of the likelihood of smoking, and probability values were determined. Interactions among the determinant variables were assessed, and are presented as relative excess risk due to interaction (RERI), attributable proportion due to interaction (AP), and synergy index (S). Synergism was reported when the synergy index was more than unity. ${ }^{16}$

\section{Results}

Because of incomplete data obtained from two regions-namely, the northern region (in which smoking was recorded for 27 people) and the central region (in which there was no recording for smoking) - they were excluded from the analysis.

Table 1 presents the weighted prevalence of current smoking in the study population according to various sociodemographic categories. The age of the study population ranged from 15 to 68 years, with a mean (SD) age of 33.1 (12.5) years for smokers and 32.9 (15.1) for non-smokers ( $p>0.05)$. The overall prevalence of smoking was $11.6 \%$, with most smokers $(78 \%)$ being in the age group between 21 and 50 years. The odds of smoking among males was 30 times that among females $(\mathrm{p}<0.001)$.

Most smokers $(59 \%)$ smoked 20 or more cigarettes per day (59\%), and $25 \%$ smoked 10-19 cigarettes per day; mean (SD) cigarette consumption was 16.8 (13.0) per day. Most smokers $(66 \%)$ had smoked for 14 years or less, and $21 \%$ had smoked for 20 years or more; mean (SD) duration of smoking was 12.2 (9.7) years. The mean monthly income in Saudi Riyals (SR) was 3100 (SD 1400) for smokers, and SR 3260 (SD 1200) for non-smokers ( $p>0.05)$.

Smoking prevalence was higher among the married population than among those in other marital-status categories $(\mathrm{OR}=5.31,95 \%$ $\mathrm{CI}=2.18$ to $12.96, \mathrm{p}<0.001)$, but this was only for the unweighted data (data stratified by marital status could not be weighted owing to lack of this information for the study population as a whole).

Current smoking was significantly associated with level of education, and smoking prevalence was higher among those who had lower and technical education (ORs $=2.43$, and 1.94, respectively; $\mathrm{p}<0.05)$. However, smoking was not associated with locality when urban and rural populations were compared $(\mathrm{OR}=1.0)$

Smoking prevalence was higher among businessmen, manual labourers, and army officers when compared with other occupations $(\mathrm{ORs}=48.74,45.54$, and 37.85, respectively; $\mathrm{p}<0.0001)$.

Smoking was more common among people living in the eastern and western regions compared with those living in the south $(O R=$ $1.63,1.53$, and 1.0 respectively; $p<0.001$ ) but this was only true for the unweighted data.

MULTIVARIATE ANALYSIS

The stepwise logistic regression analysis showed a strong association of smoking with gender $(\mathrm{OR}=27.3)$. The odds of smoking among males were 27 times those among females (table 2). Also, there was a $10 \%$ increase in the odds of smoking with a higher income or higher body mass index (BMI).

Education was an important predictor of smoking, with a $20 \%$ increase in the odds for individuals in the lower educational category of the population. 
Table 2 Results of the logistic regression analysis of the most significant determinants of smoking among the Saudi population

\begin{tabular}{lllll}
\hline Variable & $B$ & $S E$ & $O R$ & $p$ \\
\hline Sex & 3.307 & 0.179 & 27.3 & $<0.001$ \\
Marital status & 0.196 & 0.104 & 2.2 & $<0.001$ \\
Education & 0.195 & 0.099 & 1.2 & 0.05 \\
BMI & 0.123 & 0.039 & 1.1 & $<0.01$ \\
Income & 0.111 & 0.039 & 1.1 & $<0.01$ \\
Age $^{\star}$ & -0.011 & 0.004 & 0.9 & $<0.01$ \\
\hline
\end{tabular}

$\mathrm{B}=$ coefficient of regression; $\mathrm{SE}=$ standard error; $\mathrm{OR}=$ odds ratios; $\mathrm{BMI}=$ body mass index

^Age was used as a quantitative continuous variable.

When age was used as a quantitative continuous variable in the logistic model, there was a $10 \%$ decrease in odds of smoking with increasing age (table 2).

Regarding marital status, there was a twofold increase in the likelihood of smoking among married individuals compared with those in other marital-status categories.

There was a positive interaction between gender on the one hand and education, marital status, and income on the other, in determining smoking status. The interaction was multiplicative between marital status, income, and gender, but was only additive between education and gender.

\section{Discussion}

The overall prevalence of cigarette smoking in this study was $12 \%$. This is far below the prevalence figures reported from previous small-scale studies as well as community-based studies in some regions in Saudi Arabia and other Arab countries. ${ }^{11} 1217$

Smoking prevalence may have been underestimated in this study. Because smoking is not socially accepted in Saudi Arabia, some people will hide their smoking, particularly during an interview or in the presence of other family members if they are young or female. Earlier studies have shown that young Saudi students smoke more in the presence of friends than family members. ${ }^{5} 12$ Studies in other countries have also shown an underestimation of smoking prevalence. ${ }^{18}$

As in other studies, ${ }^{411}$ males smoked significantly more than females in our study. In the Saudi community there is a social stigma against smoking by women, which is seen as shameful. Other studies in the Kingdom and in other Arab countries have reported similar findings. ${ }^{17}{ }^{18}$ This differs from Western societies were female smoking is more common. ${ }^{19} 20$

Also in concordance with previous studies, smoking increased with age. A previous study has shown that smoking increased by $25 \%$ for each one-year increase in age. ${ }^{13}$

The higher smoking prevalence among married people may increase the risk of smoking initiation among children. Children who are raised in a family where parents or other family members smoke are at greater risk of initiating smoking. ${ }^{12}{ }^{19-21}$ The higher smoking prevalence among married people also raises a concern about the health effects of passive smoking among those in the same household. ${ }^{22}$

Despite the recent increase in tobacco taxes, cigarettes are still very inexpensive in the King- dom compared with other countries. Even people on low income and young children can obtain cigarettes at low cost. Previous studies in Saudi Arabia have shown that cost was not an important consideration in the decision to start smoking. ${ }^{58}$

Data on smoking patterns in Saudi Arabia are sparse. With the scarcity of national studies on smoking prevalence in the Kingdom, and in the absence of follow up and monitoring of the problem, it is difficult to anticipate the future. The long-term health consequences of smoking are not well documented in the Kingdom; however, lung cancer is now the fourth most common type of malignant disease among men. ${ }^{23}$ The growing consumption of cigarettes over the years (averaging over 2100 per capita in the early 1990s) ${ }^{24}$ might be considered as an indirect indicator of increasing smoking prevalence, in which case one would anticipate a rise in lung cancer and other smoking-related diseases in the coming decades. Nevertheless, prevalence is more likely to be a better indicator of the population's exposure to the hazards of tobacco. ${ }^{19}$ In fact, consumption and prevalence data are necessary for a full understanding of that exposure.

Because of the lag of three to four decades between the rise in smoking prevalence and the rise in the smoking-attributable mortality, ${ }^{19}$ there is lack of understanding about the risks associated with smoking in Saudi Arabia. Moreover, even in Saudi studies that have shown a high level of knowledge about the hazards of smoking, that knowledge did not affect smoking behaviour. ${ }^{58}$

The World Health Organisation (WHO) has recently provided countries with guidelines for comprehensive national tobacco control programmes. ${ }^{25}$ These guidelines include health promotion activities, media advocacy, encouragement of smoking cessation, legislative measures, fiscal measures such as tobacco taxation, and effective protective measures against involuntary exposure to secondhand smoke. ${ }^{2}$ Other strategies for the control of smoking-including pharmacological and non-pharmacological—should be adopted. ${ }^{26-31}$

In the Kingdom, there is no clear policy for tobacco control at the national level. Current control efforts are sporadic, fragmented, and not well coordinated. Although tobacco advertising and promotion are prohibited in the local media, and smoking is not allowed in government buildings or on domestic flights, there is no close monitoring for noncompliance. One highly visible and wellenforced policy has been an increase in tobacco import duties to $50 \% .^{24}$

The Saudi Smoking Control Charitable Society, during the past 14 years, has established 33 anti-smoking clinics across the country. The use of these clinics is still limited, and their smoking cessation rate is reported to be $13 \%{ }^{32}$; however, that quit rate should be interpreted with caution, because data are not available on the duration of follow up or the relapse rate. 
In a recent study, Saleh and colleagues ${ }^{33}$ reported the results of a smoking cessation programme in one city in the Kingdom. They obtained a quit rate of $38.3 \%$ at six months of follow up, and they explored psychological and behavioural factors affecting the success in quitting. That study lays the foundation for a possible large-scale intervention programme for tobacco control in the Kingdom. Such a programme should be well coordinated, comprehensive, national in scope, and consistent with the WHO's recent recommendations. Full political and technical support should be provided to facilitate implementation of those recommendations.

The authors thank Dr Fayek Al-Khwaiski for his advice on statistics and Professor Ali Mustafa for reviewing the manuscript.

1 World Health Organisation. Controlling the smoking epidemic. Geneva: WHO, 1979. (Technical Report Series No 636.) World Health Organisation. Guidelines for controlling and World Health Organisation. Guidelines for controlling
monitoring the tobacco epidemic. Geneva: WHO, 1996.

3 Saudi Arabian Central Department of Statistics. Foreign trade statistics in Saudi Arabia. Riyadh: Ministry of Finance and National Economy, 1985-1995.

4 Jarallah JS. Smoking habits of medical students at King Saud University, Riyadh. Saudi Med $\mathcal{F}$ 1992;13:510-3

5 Al-Faris EA, Al-Rajhi MM, Al-Nour MA. Smoking among females attending a health centre in Riyadh, Saudi Arabia. Ann Saudi Med 1994;15:525-8.

$6 \mathrm{Al}$ Faris EA. Smoking habits of secondary school boys in rural Riyadh. Public Health 1995;109:47-55.

7 Rowland DF, Shipster PJ. Cigarette smoking amongst Saudi School boys. Saudi Med 7 1987;8:613-8.

8 Taha A, Bener A, Nouh MS, et al. Smoking habits of King Saud University students in Riyadh. Ann Saudi Med 1991; $1: 141-3$.

9 Felimban FM. The smoking practices and attitude towards smoking of female university students in Riyadh. Saudi Med f 1993;14:220-4.

10 Saeed AW. Smoking habits of students in College of Allied Medical Sciences, Riyadh. $\mathcal{F} R$ Soc Health 1987;5:187-8.

11 Felimban FM, Jarallah JS. Smoking habits of secondary school boys in Riyadh, Saudi Arabia. Saudi Med f 1994;15:438-42.

12 El-Bedah AM. Smoking pattern in Al-Baha region of Saudi Arabia and anti-smoking programme. King Faisal University fellowship dissertation. Damman, Saudi Arabia: King Faisal University, 1989
13 Jarallah JS, Bamgboye EA, Al-Ansary LA, et al. Predictors of smoking amgboye EA, Al-Ansary LA, et al. Predictors of Riyadh, Saudi Arabia. Tobacco Control 1996;5:26-9.

14 SPCC-Win. Statistical package for social sciences, version 6, 1994.

15 Robins J, Rotnitzky A, Zhao L. Estimation of regression coefficient when a regression is not always observed. $7 \mathrm{Am}$ Stat Assoc 1994;89:846-66.

16 Rothman J. Interactions between causes. In: Modern epidemiology. Boston, Massachusetts: Little Brown, 1986:311-26.

17 Hamadeh RR. Smoking habits of medical students in Bahrain. 7 Smoking Related Dis 1994;5:189-95.

18 Awidi AS. Pattern of cigarette smoking in Jordan: a study of Great Amman area. Ann Saudi Med 1991;11:144-7.

19 Lopez AD, Collishaw NE, Piha T. A descriptive model of the cigarette epidemic in developed countries. Tobacco Control 1994;3:242-7. 20 Fiore MC, Novotny TE, Pierce JP, et al. Trends in cigarette
smoking in the United States: the changing influence of gender and race. $\mathcal{F} A M A$ 1989;261:49-55

21 Paine PA, Amal JA, Pereira MG. Association between parental and student smoking behaviour in a Brazilian Medical School. Int 7 Epidemiol 1985;14:330-2.

22 Fielding JF, Phenon KJ. Health effects of involuntary smoking. N Engl f Med 1988;319:1452-60.

23 Saudi Arabian National Cancer Registry. First report. Cancer incidence in Saudi Arabia. Riyadh: National Cancer Registry, 1994

24 World Health Organisation. Tobacco or health. A global status report. Geneva: WHO, 1997:260-1

25 World Health Organisation. Evaluating tobacco control activities: experiences and guideline principles. WHO, Geneva, 1996.

26 Silagy CA, Fowler GU. Systematically reviewing the effectiveness of pharmacological and nonpharmacological smoking cessation methods. F Smoking Related Dis 1994;5(suppl 1):295-303.

27 Kunze M. Overview of the comprehensive approach to tobacco control. F Smoking Related Dis 1994;5(suppl tobacco cont $1305-7$.

28 Chapman S. Tobacco control. BMF 1996;313:97-9.

29 Patten CA, Gilpin E, Cavin SW, et al. Workplace smoking policy and changes in smoking behaviour in California: a suggested association. Tobacco Control 1995;4:36-41.

30 Morgan-Jone RL, Mattu GS, Hughes O, et al. Do smoking cessation clinics work in district general hospitals? $\mathcal{F}$ Smoking Relat Dis 1994;5(suppl 1):247-51.

31 Silagy C, Mant D, Fowler G, et al. Meta-analysis on efficiency of nicotine replacement therapies in smoking cessation. Lancet 1994;343:139-42.

32 Saudi Smoking Control Charitable Society. Report of activities 1416-1417. Riyadh: Saudi Smoking Control Charitable Society (In Arabic).

33 Saleh MA, Farghaly AB. Determinants of outcome among smokers in a smoking cessation program. F Fam Commun Med 1997;4:22-31. 